\title{
A biologically based damage assessment model to enhance aquacultural water quality management
}

\author{
Jeng-Wei Tsai, Chung-Min Liao*, Vivian Hsiu-Chuan Liao \\ Ecotoxicological Modeling Center, Department of Bioenvironmental Systems Engineering, \\ National Taiwan University, Taipei 10617, Taiwan, ROC
}

Received 24 March 2005; received in revised form 20 May 2005; accepted 24 May 2005

\begin{abstract}
The lethal concentration for $50 \%$ of aquacultural animals $\left(\mathrm{LC}_{50}\right)$-based tests determines the external effect concentration (EEC) following certain statistical models, revealing that no biologically based mechanistic information and only statistical interpretations of its model parameters could be made. The purpose of this paper is to determine the survival risk of waterborne metals toward farmed species with respect to lethality based on biologically based mechanistic models. Here we study a biologically based mechanistic damage assessment model (DAM) compared with a pharmacodynamic (PD)-based critical area under the curve (CAUC) model to demonstrate the ability of predicting the internal effect concentration (IEC) and survival rate of farmed species. We tested the proposed models using published acute toxicity and accumulation data for two farmed species, tilapia (Orechromis mossambicus) exposed to arsenic (As) and abalone (Haliotis diversicolor supertexta) exposed to zinc ( $\mathrm{Zn}$ ), to compare observed and predicted $\mathrm{LC}_{50}$ and IEC and, subsequently, to predict the survival rate. Our analyses demonstrate that the DAM- and PD-based survival models performed well and proved its usefulness as a tool in the quantification of risk assessment in aquacultural ecosystems. The study also supports the suggestion that replacing exposure-based EECs by IECs is a first step toward a measure for inherent toxicity and can be used to improve the construction of future environmental quality criteria programs aimed at protecting and restoring the rapidly degrading aquacultural ecosystems.
\end{abstract}

(C) 2005 Elsevier B.V. All rights reserved.

Keywords: Damage; Internal effect concentration; Pharmacodynamics; Risk; Survival; Abalone; Tilapia; Waterborne metals

\section{Introduction}

Due to anthropogenic activities or geochemical cycling, heavy metal pollution is a serious problem

\footnotetext{
* Corresponding author. Tel.: +88622363 4512; fax: +886 2 23626433.

E-mail address: cmliao@ntu.edu.tw (C.-M. Liao).
}

and is one of the most studied aquacultural ecosystem problems. Aquacultural organisms may bioaccumulate trace metals in their tissues and consequently threaten themselves directly. Standard toxicity tests performed in the laboratory are used extensively to predict the effects of chemicals in aquatic ecosystems. This is the first step in determining the environmental risk of a chemical to aquatic species. We usually use a 
preselected time span to determine the median lethal concentration $\left(\mathrm{LC}_{50}\right)$. $\mathrm{LC}_{50}$-based tests determine the external effect concentration (EEC), although the observed effect depends on the intrinsic toxicity or biokinetic behavior of the chemical in the aquatic animal. Therefore, the $\mathrm{LC}_{50}$-based parameters are mostly model-dependent, yet the models usually employed, such as logit and probit, have no biologically based assumptions that allow questions about the relevancy of such models. Hill (1910) has tried to employ a log-logistic model to account for an interaction between the xenobiotic and the receptor-mediated active compound in the organism. However, the conventional analysis of bioassays does not account for biological significance.

Normally, internal effect concentration (IEC) is not measured in toxicity experiments; therefore, we usually treat IEC as a hidden variable in that the tissue concentration is scaled with the bioconcentration factor (BCF) in order to obtain a quantity that is directly proportional to the tissue concentration yet has the dimension of an EEC (Freidig et al., 1999; Lee et al., 2002a). A different approach of measuring the acute toxicity of chemicals is based on IECs, instead of EECs. External $\mathrm{LC}_{50}$ values are then replaced by lethal body concentrations (LBCs) (French-McCay, 2002). The LBC is the concentration of a chemical within an organism at the time of death and can be estimated from experiments in which the increase of mortality with exposure time is observed in conjunction with the concentration of chemicals in the body.

The current procedures in bioassays consist of observing lethality at fixed times, which can lead to the determination of $\mathrm{LC}_{50}$ endpoints, rather than survival curves. There is then a statistical dependence of $\mathrm{LC}_{50}$ data at consecutive times because they concern the same organisms. It is more robust and powerful to use the dose-time-response data than just the $\mathrm{LC}_{50}$ values. Survival models also consider raw experimental data as time to death versus concentration. They have an intrinsically greater statistically power, yet any biological interpretation is limited.

Based on toxicological principles, the mechanisms through which the dose at the target site elicits the ultimate adverse response are described by pharmacodynamic (PD) scheme and referred to as the action of the effect dose at the target site. Recently, Verhaar et al. (1999) and Legierse et al. (1999) have developed a PD-based model, the critical area under the curve (CAUC) model, to describe the time course of $\mathrm{LC}_{50}$ data for chemicals that act through the irreversible interaction between chemicals and receptors. The CAUC model could be applied to depict the acute toxicity and to estimate incipient $\mathrm{LC}_{50}$ values and IECs of waterborne chemicals in organisms. PDbased models have been continuously developed for the understanding of bioassay data (Liao et al., 2002; Liao and Ling, 2004).

One biologically based mechanistic model based on the damage assessment model (DAM) was developed by Lee et al. (2002b) to describe and predict time-dependent toxicity data. DAM depicts the modes of action, including rapid reversible binding to the target site as well as to those that act with irreversible binding. Thus, both of the critical body residue (CBR) and the CAUC models are extreme cases of the DAM (Lee et al., 2002b). DAM assumes that death occurs when the cumulative damage reaches a critical level and was described by a combination of both firstorder toxicokinetic and toxicodynamic models. Damage is assumed to accumulate in proportion to the accumulated residue and damage recovery in proportion to the cumulative damage when damage is reversible. The time-dependent $\mathrm{LC}_{50}$ data are determined by both a damage recovery rate and an elimination rate, suggesting that the critical cumulative damage is the determinant of the time-concentration response relationship and not simply the CAUC. DAM is originally based on a mathematical model DEBtox (Bedaux and Kooijman, 1994; Widianarko and van Straalen, 1996), where DEBtox relates survivorship to toxicokinetics by assuming that the probability of dying (i.e., the hazard rate) is related to the concentration of the toxicant in the organism. DEBtox models have also been extensively applied in the fields of ecological risk assessment (Pery et al., 2001; Bonnoment et al., 2002).

The objective of this paper is to determine the survival risk of waterborne metals toward farmed species with respect to lethality based on a biologically based DAM compared with a PD-based CAUC model to demonstrate the ability in predicting IEC and survival rate. Our purposed models are able to describe time-dependent toxicity data, which contain information about the dynamic aspect of the occur- 
rence of effects. The models were adapted to fit the data from toxicity and accumulation experiments simultaneously to reveal mechanistic information on metal toxicity on aquatic animals. We also make an exploratory analysis on the basis of toxicokinetic parameters to predict the IEC and survival of farmed species based on the EEC.

We test the proposed models using published acute toxicity and accumulation data for two farmed species, tilapia (Orechromis mossambicus) exposed to arsenic (As) and abalone (Haliotis diversicolor supertexta) exposed to zinc ( $\mathrm{Zn}$ ), to compare observed and predicted $\mathrm{LC}_{50}$ and IEC and, subsequently, to predict the survival rate. Arsenic and $\mathrm{Zn}$ were chosen for practical as well as theoretical reasons, with the availability of reasonable amounts of suitable information as the primary consideration. Generally, as prerequisites for data suitability, we required exposure and whole-body As and $\mathrm{Zn}$ levels measured by accepted analytical techniques. In this respect, we considered experimental exposure data to be acceptable only when whole body concentration data were available and when the exposure duration was at least 14 days. Our previous published As-tilapia and $\mathrm{Zn}$-abalone databases meet this principle. On the other hand, As and $\mathrm{Zn}$ were chosen in this study because they represent metals of general concern in terms of environmental protection and can span the continuum from nutritionally essential to nonessential.

\section{Materials and methods}

\subsection{Damage-based survival model}

Bedaux and Kooijman (1994) have developed a biologically based model to investigate the relationships among body residues, cumulative damage, and survival rate in order to describe the time-dependent survival probability that can be expressed as the exponential of cumulative hazard as:

$S(t)=\mathrm{e}^{-H(t)}$,

where $S(t)$ is the probability to survival until time $t$ and $H(t)$ is the cumulative hazard (dimensionless). In DAM-based survival modeling, a proportionality constant $k_{3}$ (dimensionless) is introduced to relate cumulative hazard and cumulative damage level, which is a measure of the toxicity of the chemical. The cumulative hazard can be refined as $H(t)=k_{3} D(t)$, where $k_{3}$ is a dimensionless coefficient, $D(t)$ is referred to as the time-dependent cumulative damage (dimensionless) that can be derived from the solution of first-order damage accumulation model, $\mathrm{d} D(t) / \mathrm{d} t=k_{\mathrm{a}} C_{\mathrm{wb}}(t)-$ $k_{\mathrm{r}} D(t)$ and given as:

$D(t)=k_{\mathrm{a}} \frac{k_{\mathrm{u}}}{k_{\mathrm{e}}} C_{\mathrm{w}}\left(\frac{\mathrm{e}^{-k_{\mathrm{r}} t}-\mathrm{e}^{-k_{\mathrm{e}} t}}{k_{\mathrm{r}}-k_{\mathrm{e}}}+\frac{1-\mathrm{e}^{-k_{\mathrm{r}} t}}{k_{\mathrm{r}}}\right)$,

where $k_{\mathrm{a}}$ is the damage accumulation rate $\left(\mathrm{g} \mu \mathrm{g}^{-1}\right.$ $\left.\mathrm{h}^{-1}\right), k_{\mathrm{r}}$ is the damage recovery rate constant $\left(\mathrm{h}^{-1}\right), k_{\mathrm{u}}$ is the uptake rate constant $\left(\mathrm{mL} \mathrm{g}^{-1} \mathrm{~h}^{-1}\right), k_{\mathrm{e}}$ is the elimination rate constant $\left(\mathrm{h}^{-1}\right)$, and ratio of $k_{\mathrm{u}}$ and $k_{\mathrm{e}}$ is known as the BCF $\left(\mathrm{mL} \mathrm{g}^{-1}\right), C_{\mathrm{wb}}(t)=\mathrm{BCF} C_{\mathrm{w}}$ $\left(1-\mathrm{e}^{-k_{\mathrm{e}} t}\right)$ is the toxicant concentration in organisms that is calculated from the first-order bioaccumulation model $\mathrm{d} C_{\mathrm{wb}}(t) / \mathrm{d} t=k_{\mathrm{u}} C_{\mathrm{w}}-k_{\mathrm{e}} C_{\mathrm{wb}}(t)$, and $C_{\mathrm{w}}$ is the waterborne toxicant concentration $\left(\mu \mathrm{g} \mathrm{mL}{ }^{-1}\right)$. This leads to the following expression for $H(t)$ as (Lee et al., 2002b):

$H(t)=k_{3} k_{\mathrm{a}} \frac{k_{\mathrm{u}}}{k_{\mathrm{e}}} C_{\mathrm{w}}\left(\frac{\mathrm{e}^{-k_{\mathrm{r}} t}-\mathrm{e}^{-k_{\mathrm{e}} t}}{k_{\mathrm{r}}-k_{\mathrm{e}}}+\frac{1-\mathrm{e}^{-k_{\mathrm{r}} t}}{k_{\mathrm{r}}}\right)$,

where Bedaux and Kooijman (1994) introduced a constant, called "killing rate" $\left(k_{\dagger}\right)$, to represent a measure for the toxicity of a compound and has the dimension [(tissue concentration $\times$ time $)^{-1}$ ] in that $k_{\dagger}=k_{3} k_{\mathrm{a}}$. The killing rate is the proportionality factor that describes the relation between the accumulated hazard and the cumulative damage. The DAM modeling assumed that death occurs when the accumulative damage accrues to a critical lethal level $\left(D_{\mathrm{L}}\right)$. If $D(t)$ can be denoted by $D_{\mathrm{L}, 50}$ for the damage level that causes $50 \%$ mortality, the damage-based median lethal concentration $\left(\mathrm{LC}_{50}(t)\right)$ and lethal body concentration $\left(C_{\mathrm{L}, 50}(t)\right)$ can be derived, respectively, from the first-order damage accumulation model and the firstorder one-compartment bioaccumulation model as (Lee et al., 2002b):

$\mathrm{LC}_{50}(t)=\frac{D_{\mathrm{L}, 50} / k_{\mathrm{a}}}{\left(\frac{\mathrm{e}^{-k_{\mathrm{r}} t}-\mathrm{e}^{-k_{\mathrm{e}} t}}{k_{\mathrm{r}}-k_{\mathrm{e}}}+\frac{1-\mathrm{e}^{-k_{\mathrm{r}} t}}{k_{\mathrm{r}}}\right)} \mathrm{BCF}^{-1}$,

and

$C_{\mathrm{L}, 50}(t)=\frac{D_{\mathrm{L}, 50} / k_{\mathrm{a}}}{\left(\frac{\mathrm{e}^{-k_{\mathrm{r}} t}-\mathrm{e}^{-k_{\mathrm{e}} t}}{k_{\mathrm{r}}-k_{\mathrm{e}}}+\frac{1-\mathrm{e}^{-k_{\mathrm{r}} t}}{k_{\mathrm{r}}}\right)}\left(1-\mathrm{e}^{-k_{\mathrm{e}} t}\right)$, 
where $D_{\mathrm{L}, 50} / k_{\mathrm{a}}$ is a coefficient that reflects the compound equivalent toxic damage level required for $50 \%$ mortality $\left(\mu \mathrm{g} \mathrm{h} \mathrm{g}^{-1}\right)$. We depicted the relationship between the median lethal concentration $\left(\mathrm{LC}_{50}(t)\right)$ and the time-dependent cumulative damage $(D(t))$ from Eqs. (2) and (4) as $\mathrm{LC}_{50}(t)=D_{\mathrm{L}, 50} C_{\mathrm{w}} / D(t)$. It can be rearranged to a new expression as:

$\frac{D(t)}{D_{\mathrm{L}, 50}}=\frac{C_{\mathrm{w}}}{L C_{50}(t)}$,

where $D(t) / D_{\mathrm{L}, 50}$ is the relative accumulation damage level, representing the ability to induce a $50 \%$ mortality when organisms are exposed to a toxicant. Whenever the predicted result exceeds the value of 1.0 , the mortality of $50 \%$ will occur in a given exposure scenario. Therefore, Eq. (6) provides a prediction tool to assess the lethality of external aqueous concentrations to organisms in a given time span.

With sufficient $\mathrm{LC}_{50}(t)$ and $C_{\mathrm{L}, 50}(t)$ data of a given duration range, it is possible to estimate the best-fit values of the $D_{\mathrm{L}, 50} / k_{\mathrm{a}}, k_{\mathrm{r}}$ in Eqs. (4) and (5) and $k_{\dagger}$ in Eq. (3) by using a nonlinear regression technique.

\subsection{Pharmacodynamic-based survival model}

The PD-based survival model has the form as (Liao et al., 2002):

$S(t)=1-M(t)$,

where $M(t)$ is the time-dependent mortality (dimensionless). In PD modeling, the relationship between dose effect and dose concentration is commonly expressed by the Hill equations (Bourne, 1995; De Vries, 1996), suggesting that mortality functions can be estimated from observed mortality percentages in exposure regimes and can be expressed as functions of waterborne concentration $\left(C_{\mathrm{w}}\right)$ and $\mathrm{LC}_{50}(t)$ data as:

$M(t)=\frac{M_{\max } C_{\mathrm{w}}^{n}}{\mathrm{LC}_{50}^{n}(t)+C_{\mathrm{w}}^{n}}$,

where $C_{\mathrm{w}}$ is the toxicant concentration in water $(\mu \mathrm{g}$ $\left.\mathrm{mL}^{-1}\right), M_{\max }$ is the maximum dose effect, and $n$ is the Hill coefficient. With sufficient data of percent mortality over a suitable concentration in water associated with the specific interval of $\mathrm{LC}_{50}(t)$ data, we can estimate best-fit values of Hill coefficient appearing in Eq. (8) by a nonlinear regression technique. $\mathrm{LC}_{50}(t)$ causes an effect equal to $50 \%$ of the $M_{\max }$, which can be predicted from the first-order bioaccumulation model based on the assumption of the CAUC model (Liao et al., 2002, 2004).

On the concept of the CAUC model, adverse effect is associated with a critical amount of irreversible "covalenty occupied" target site and the concentration of inhibited molecules in the target tissue is constant (Verhaar et al., 1999). De Vries (1996) and Legierse et al. (1999) suggested that the critical irreversible target occupation could be expressed with the CAUC, which describes the time-integrated concentration of the molecular inhibition. In employing the CAUC model, $\mathrm{LC}_{50}(t)$ can be determined by (Legierse et al., 1999):

$$
\begin{aligned}
\operatorname{LC}_{50}(t)= & \frac{\mathrm{AUC}}{\mathrm{BCF}}\left(\frac{k_{\mathrm{e}}}{k_{\mathrm{e}} t+\mathrm{e}^{-k_{\mathrm{e}} t}-1}\right) \\
& +\operatorname{LC}_{50}(\infty),
\end{aligned}
$$

where AUC is the area under the concentration of toxicant in organism versus time curve $\left(\mu \mathrm{g} \mathrm{h} \mathrm{g}^{-1}\right)$. Substituting $C_{\mathrm{w}}$ in the first-order bioaccumulation model by $\mathrm{LC}_{50}(t)$ in Eq. (9) and regarding $C_{\mathrm{wb}}(t)$ as the $C_{\mathrm{L}, 50}(t)$, lead to the following expression for $C_{\mathrm{L}, 50}(t)$ as:

$$
\begin{aligned}
C_{\mathrm{L}, 50}(t)= & \operatorname{AUC}\left(\frac{k_{\mathrm{e}}\left(1-\mathrm{e}^{-k_{\mathrm{e}} t}\right)}{k_{\mathrm{e}} t+\mathrm{e}^{-k_{\mathrm{e}} t}-1}\right) \\
& +\operatorname{BCF}\left(1-\mathrm{e}^{-k_{\mathrm{e}} t}\right) \mathrm{LC}_{50}(\infty) .
\end{aligned}
$$

The assumption of reversible binding in the critical burden residue (CBR) model, $\mathrm{LC}_{50}(t)$, can also be predicted from knowledge of the exposure time $(t)$, depuration rate constant $\left(k_{\mathrm{e}}\right), \mathrm{BCF}$, and $C_{\mathrm{L}, 50}$ by firstorder bioaccumulation model as (McCarty and Mackay, 1993):

$\mathrm{LC}_{50}(t)=\frac{C_{\mathrm{L}, 50}}{\operatorname{BCF}\left(1-\mathrm{e}^{-k_{\mathrm{e}} t}\right)}$.

When the exposure time approaches infinity, Eq. (11) gives a relation among $\mathrm{LC}_{50}(\infty), C_{\mathrm{L}, 50}$, and $\mathrm{BCF}$ as:

$C_{\mathrm{L}, 50}=\mathrm{LC}_{50}(\infty) \mathrm{BCF}$,

The $C_{\mathrm{L}, 50}$ will be constant and thus independent of exposure concentration and time of death. The inte- 
grated scheme of our conceptual models for the DAM- and PD-based survival analyses is schematically illustrated in Fig. 1.
The majority of the data used in this investigation were taken from published works on the acute toxicity of waterborne As to farmed tilapia O. mossambicus

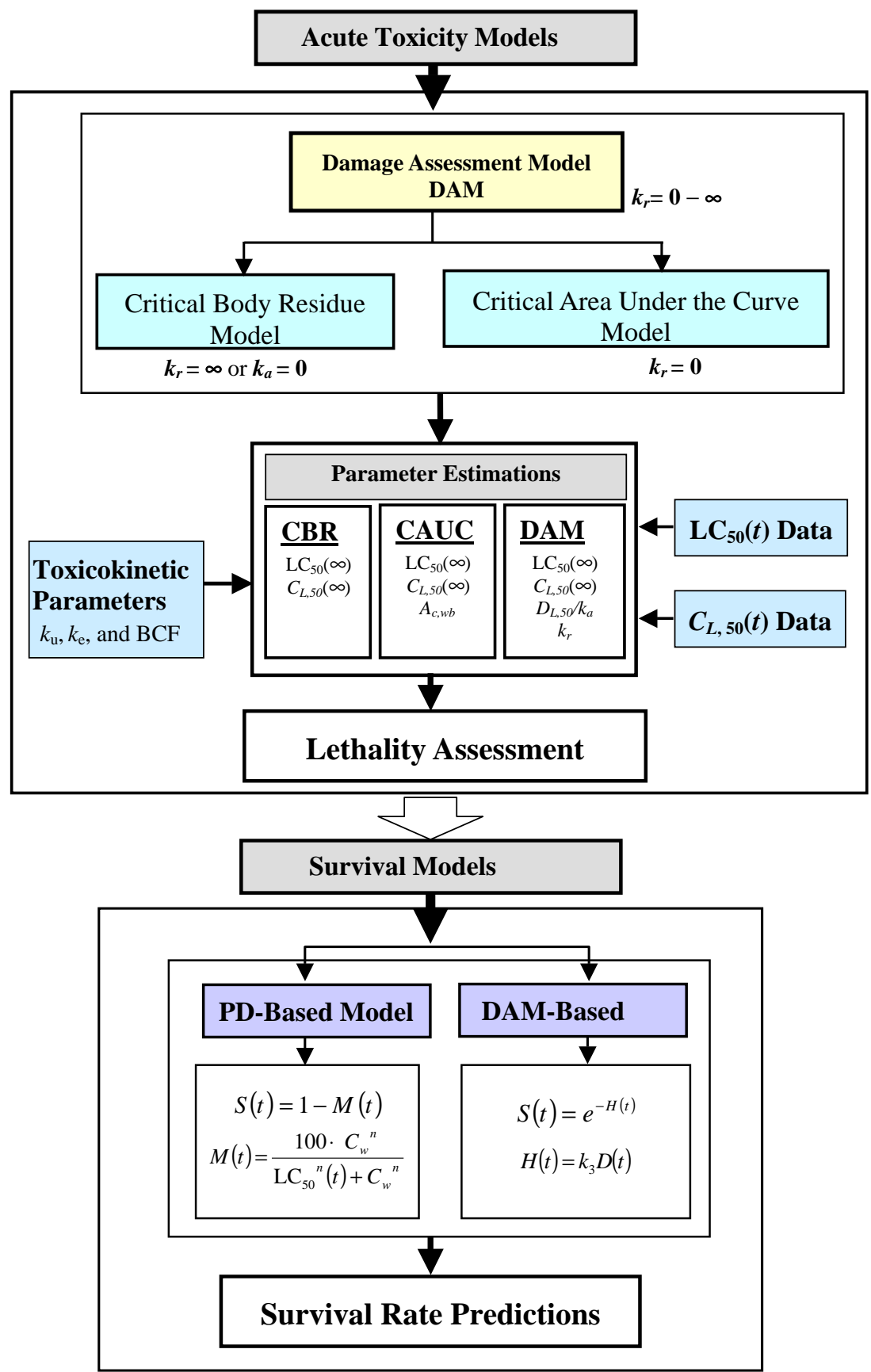

Fig. 1. Schematic illustration of the principal algorithms and approach phase for using the damage assessment model- and pharmacodynamicbased survival models applied to bioassay analyses. 
Table 1

Experimental conditions (mean \pm S.D.) and available data in tilapia and abalone acute toxicity bioassays

\begin{tabular}{|c|c|c|c|c|c|c|c|}
\hline \multirow[t]{2}{*}{ Bioassay system } & \multirow[t]{2}{*}{ Time (h) } & \multirow[t]{2}{*}{ Temperature $\left({ }^{\circ} \mathrm{C}\right)$} & \multirow[t]{2}{*}{$\mathrm{pH}$} & \multicolumn{2}{|l|}{ Body size } & \multirow[t]{2}{*}{ Data adopted } & \multirow[t]{2}{*}{ Reference } \\
\hline & & & & Weight (g) & Length (mm) & & \\
\hline As-tilapia system & 96 & $24.7 \pm 0.2$ & $7.9 \pm 0.1$ & $17.6 \pm 1.6$ & $148.7 \pm 6.5$ & $\mathrm{LC}_{50}(t)$ & Liao et al., 2003 \\
\hline Zn-abalone system & 168 & $25 \pm 1.5$ & $7.8 \pm 0.2$ & $6.6 \pm 0.7$ & $3.4 \pm 0.43$ & $\mathrm{LC}_{50}(t), C_{\mathrm{L}, 50}(t)$ & Liao et al., 2002 \\
\hline
\end{tabular}

(Liao et al., 2003) and of $\mathrm{Zn}$ to farmed abalone $H$. diversicolor supertexta (Liao et al., 2002) in that $\mathrm{Zn}-$ abalone system also contained IEC data. Table 1 lists the main experimental conditions used in the acute toxicity tests for As-tilapia and $\mathrm{Zn}$-abalone systems. To evaluate the DAM, $\mathrm{LC}_{50}$ data were fitted according to Eq. (4), whereas the $\mathrm{LC}_{50}$ data were fitted based on Eq. (9) for the CAUC model and Eq. (11) for the CBR model. In $\mathrm{Zn}$-abalone system, $C_{\mathrm{L}, 50}$ data were fitted based on Eqs. (5), (10), and (12) for the DAM, CAUC, and CBR models, respectively; whereas Eqs. (5), (10), and (12) were also used, respectively, to predict $C_{\mathrm{L}, 50}(t)$ profiles for the three models in the As-tilapia system. The toxicokinetic-based input parameters including uptake rate constant $\left(k_{\mathrm{u}}\right)$, elimination rate constant $\left(k_{\mathrm{e}}\right)$, and $\mathrm{BCF}$ for As-tilapia and $\mathrm{Zn}$-abalone systems are listed in Tables 2 and 3, respectively. Tables 2 and 3 also list the input para-

Table 2

Input parameters and parameter estimations for CBR, CAUC, and DAM models applied to the $\mathrm{LC}_{50}(t)$ data and $C_{\mathrm{L}, 50}(t)$ predictions of the As-tilapia system

\begin{tabular}{|c|c|c|c|}
\hline As-tilapia system & DAM & CAUC & CBR \\
\hline \multicolumn{4}{|l|}{ Input parameters $^{\mathrm{a}}$} \\
\hline$k_{\mathrm{u}}\left(\mathrm{mL} \mathrm{g}^{-1} \mathrm{~h}^{-1}\right)$ & $0.016(0.95)$ & & \\
\hline$k_{\mathrm{e}}\left(\mathrm{h}^{-1}\right)$ & $0.0032(0.97)$ & $\begin{array}{l}0.0032 \\
(0.97)\end{array}$ & $\begin{array}{l}0.0032 \\
(0.97)\end{array}$ \\
\hline $\mathrm{BCF}\left(\mathrm{mL} \mathrm{g}^{-1}\right)$ & & 5.06 & 5.06 \\
\hline \multicolumn{4}{|l|}{ Parameter estimates ${ }^{\mathrm{b}}$} \\
\hline$D_{\mathrm{L}, 50} / k_{\mathrm{a}}\left(\mu \mathrm{g} \mathrm{h} \mathrm{g}^{-1}\right)$ & $1.59(0.82)$ & & \\
\hline$k_{\mathrm{r}}\left(\mathrm{h}^{-1}\right)$ & $18.85(0.82)$ & & \\
\hline $\mathrm{LC}_{50}(\infty)\left(\mu \mathrm{g} \mathrm{mL}^{-1}\right)$ & 5.96 & $\begin{array}{l}25.57 \pm 5.21 \\
(0.79)\end{array}$ & 5.97 \\
\hline $\operatorname{AUC}\left(\mu \mathrm{g} \mathrm{h}^{-1}\right)$ & & $\begin{array}{l}215.52 \pm 55.78 \\
(0.79)\end{array}$ & \\
\hline$C_{\mathrm{L}, 50}(\infty)\left(\mu \mathrm{g} \mathrm{g}^{-1}\right)$ & 30.15 & 60.76 & $\begin{array}{l}30.05 \pm 2.54 \\
(0.82)\end{array}$ \\
\hline$k_{\dagger}\left(\mu \mathrm{g} \mathrm{g}^{-1} \mathrm{~h}^{-1}\right)$ & $0.36(0.80)$ & & \\
\hline
\end{tabular}

${ }^{\mathrm{a}}$ Determined from 15-day exposure experiment: $k_{\mathrm{u}}=0.016 \pm$ $0.002 ; k_{\mathrm{e}}=0.0032 \pm 0.0006$.

${ }^{\mathrm{b}}$ Estimated from $\mathrm{LC}_{50}(t)$ data. meters used in Eqs. (5), (10), and (12) to predict $C_{\mathrm{L}, 50}(t)$ profiles in the As-tilapia system.

All curve fittings were performed using the nonlinear regression option of the Statistica ${ }^{\circledR}$ software package (StatSoft, Tulsa, OK, USA). Statistica ${ }^{\circledR}$ was also used to calculate the coefficient of determination

Table 3

Input parameters and parameter estimations for CBR, CAUC, and DAM models fitted to the $\mathrm{LC}_{50}(t)$ and $C_{\mathrm{L}, 50}(t)$ data of the $\mathrm{Zn}-$ abalone system

\begin{tabular}{|c|c|c|c|}
\hline $\mathrm{Zn}$-abalone system & DAM & CAUC & CBR \\
\hline \multicolumn{4}{|l|}{ Input parameters $^{\mathrm{a}}$} \\
\hline 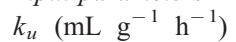 & $4.25(0.96)$ & & \\
\hline$k_{e}\left(\mathrm{~h}^{-1}\right)$ & $0.025(0.97)$ & $0.025(0.97)$ & $0.025(0.97)$ \\
\hline $\mathrm{BCF}\left(\mathrm{mL} \mathrm{g}^{-1}\right)$ & & 167 & 167 \\
\hline \multicolumn{4}{|l|}{ Parameter estimates ${ }^{\mathrm{b}}$} \\
\hline $\begin{array}{l}D_{\mathrm{L}, 50} / k_{\mathrm{a}} \\
\quad\left(\mu \mathrm{g} \mathrm{h}^{-1}\right)\end{array}$ & $10.89(0.94)$ & & \\
\hline$k_{r}\left(\mathrm{~h}^{-1}\right)$ & $12.29(0.94)$ & & \\
\hline $\begin{array}{l}\mathrm{LC}_{50}(\infty) \\
\quad\left(\mu \mathrm{g} \mathrm{mL} L^{-1}\right)\end{array}$ & 0.80 & $\begin{array}{l}1.26 \pm 0.02 \\
(0.92)\end{array}$ & 0.81 \\
\hline AUC $\left(\mu \mathrm{g} \mathrm{h}^{-1}\right)$ & & $\begin{array}{l}386.69 \pm 21.38 \\
(0.92)\end{array}$ & \\
\hline $\begin{array}{l}C_{\mathrm{L}, 50}(\infty) \\
\quad\left(\mu \mathrm{g} \mathrm{g}^{-1}\right)\end{array}$ & 133.84 & 210.55 & $\begin{array}{l}134.68 \pm 5.54 \\
(0.94)\end{array}$ \\
\hline$k_{\dagger}\left(\mu \mathrm{g} \mathrm{g}^{-1} \mathrm{~h}^{-1}\right)$ & $0.064(0.94)$ & & \\
\hline \multicolumn{4}{|l|}{ Parameter estimates ${ }^{\mathrm{c}}$} \\
\hline $\begin{array}{l}D_{\mathrm{L}, 50} / k_{\mathrm{a}} \\
\quad\left(\mu \mathrm{g} \mathrm{h} \mathrm{g}^{-1}\right)\end{array}$ & 8.27 & & \\
\hline$k_{r}\left(\mathrm{~h}^{-1}\right)$ & 30.74 & & \\
\hline $\begin{array}{l}\mathrm{LC}_{50}(\infty) \\
\quad\left(\mu \mathrm{g} \mathrm{mL} L^{-1}\right)\end{array}$ & 1.52 & $\begin{array}{l}1.58 \pm 0.02 \\
(0.94)\end{array}$ & $\begin{array}{l}0.87 \pm 0.012 \\
(0.93)\end{array}$ \\
\hline $\operatorname{AUC}\left(\mu \mathrm{g} \mathrm{h}^{-1}\right)$ & & $\begin{array}{l}1214.15 \pm 91.47 \\
(0.94)\end{array}$ & \\
\hline $\begin{array}{l}C_{\mathrm{L}, 50}(\infty) \\
\quad\left(\mu \mathrm{g} \mathrm{g}^{-1}\right)\end{array}$ & 254.10 & 263.86 & 135.27 \\
\hline$k_{\dagger}\left(\mu \mathrm{g} \mathrm{g}^{-1} \mathrm{~h}^{-1}\right)$ & $0.083(0.94)$ & & \\
\hline
\end{tabular}

${ }^{\text {a }}$ Determined from 14-day exposure experiment: $k_{\mathrm{u}}=4.25 \pm$ $0.978 ; k_{\mathrm{e}}=0.02546 \pm 0.018$.

${ }^{\mathrm{b}}$ Estimated from $\mathrm{LC}_{50}(t)$ data.

${ }^{\mathrm{c}}$ Estimated from $\mathrm{C}_{L, 50}(t)$ data. 
$\left(r^{2}\right)$ and to execute all statistical analyses including the optimal fits of the $\mathrm{LC}_{50}(t), C_{\mathrm{L}, 50}(t)$, and survival rate data. Eventually, we employed the DAM-based model (Eq. (1)) and PD-based survival model (Eq. (7)) to simulate the concentration-dependent survival rates of two chemical-species combinations in the 96-h duration and further to predict the concentration-dependent survival rates in different durations in these two systems.

\section{Results}

\subsection{Fitting toxicity models to $L C_{50}(t)$ and $C_{L, 50}(t)$} data

The optimal fits of the DAM, CAUC, and CBR models to the observed $\mathrm{LC}_{50}(t)$ data of As-tilapia as well as $\mathrm{LC}_{50}(t)$ and $C_{\mathrm{L}, 50}(t)$ data of $\mathrm{Zn}$-abalone systems are presented, respectively, in Fig. 2A, C, and D.
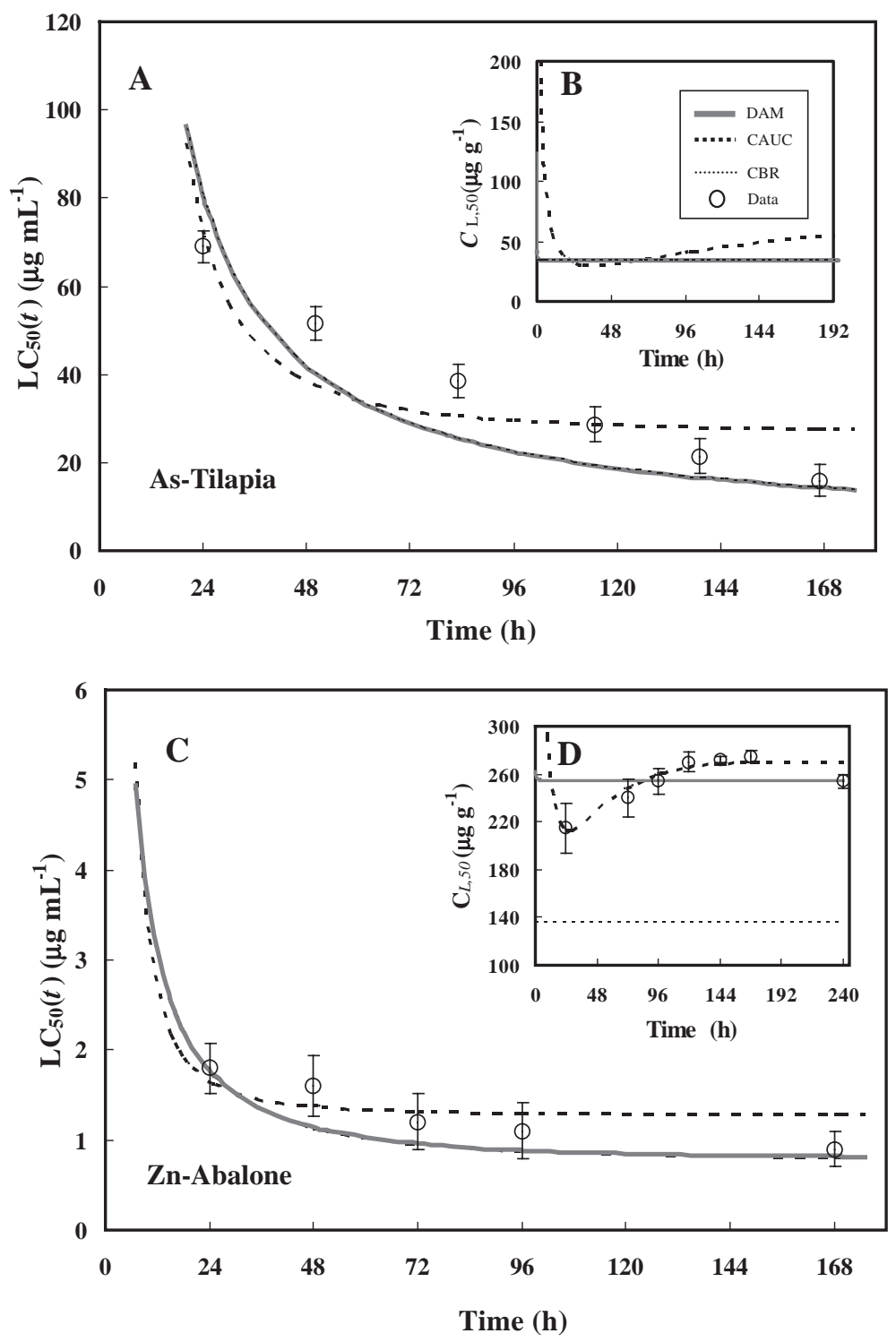

Fig. 2. Optimal fits of (A) $\mathrm{LC}_{50}(t)$ data and (B) predicted $C_{\mathrm{L}, 50}(t)$ profiles in the As-tilapia system and optimal fits of $(\mathrm{C}) \mathrm{LC}_{50}(t)$ data and $(\mathrm{D})$ $C_{\mathrm{L}, 50}(t)$ data in the $\mathrm{Zn}$-abalone system applied by DAM, CAUC, and CBR models. 
Table 4

A comparison between $\mathrm{LC}_{50}\left(\mu \mathrm{g} \mathrm{mL} \mathrm{m}^{-1}\right)$ data and predicted values from PD- and DAM-based survival models for selected time intervals in which values of $95 \%$ confidence interval (CI) are given in parentheses

\begin{tabular}{lcll}
\hline Time $(\mathrm{h})$ & $\mathrm{LC}_{50}$ data & $\begin{array}{l}\text { PD-based } \\
\text { model }\end{array}$ & $\begin{array}{l}\text { DAM-based } \\
\text { model }\end{array}$ \\
\hline \multicolumn{2}{l}{ As-tilapia system } \\
24 & $69.06(65.81-72.31)$ & 69.06 & 80.45 \\
48 & $51.52(48.11-54.93)$ & 51.52 & 41.68 \\
72 & $38.44(34.85-42.03)$ & 38.44 & 28.88 \\
96 & $28.68(24.92-32.44)$ & 28.68 & 22.5 \\
120 & $21.41(17.59-25.23)$ & 21.41 & 18.61 \\
144 & $15.98(12.07-19.89)$ & 15.98 & 16.08 \\
& & & \\
$Z n-$ abalone & system & & \\
24 & $1.8(1.52-2.08)$ & 1.8 & 1.74 \\
48 & $1.6(1.26-1.94)$ & 1.6 & 1.12 \\
72 & $1.2(0.89-1.52)$ & 1.2 & 0.95 \\
96 & $1.1(0.83-1.59)$ & 1.1 & 0.88 \\
168 & $0.9(0.77-1.18)$ & 0.9 & 0.81 \\
\hline
\end{tabular}

The estimated model-specific parameters of different chemical-species combinations are listed in Tables 2 and 3 .

Fig. 2A and $\mathrm{C}$ show that both DAM and CBR models describe the data in a more accurate way, depending on the estimated incipient $\mathrm{LC}_{50}$ values of the DAM $\left(\mathrm{LC}_{50}(\infty)=5.96 \mu \mathrm{g} \mathrm{mL}^{-1}\right)$ and CBR model $\left(\mathrm{LC}_{50}(\infty)=5.97 \mu \mathrm{g} \mathrm{mL}^{-1}\right)$. The DAM-based model shows a good agreement with the observed $\mathrm{LC}_{50}(t)$ values at $t=120 \mathrm{~h}$ and $144 \mathrm{~h}$ in the As-tilapia system (all fall within the $95 \% \mathrm{CI}$ values of observed $\mathrm{LC}_{50}$ data) (Table 4). A similar result also occurs in the $\mathrm{Zn}-$ abalone system, in that the estimated incipient $\mathrm{LC}_{50}$ values of the DAM and CBR model are 0.80 and 0.81 $\mu \mathrm{g} \mathrm{mL}^{-1}$ (Table 3), respectively, whereas DAM-based predicted $\mathrm{LC}_{50}$ values also show a good agreement with the observed $\mathrm{LC}_{50}$ value at $t=72 \mathrm{~h}, 96 \mathrm{~h}$, and $168 \mathrm{~h}$ (Table 4). The average coefficients of determination $\left(r^{2}, p<0.05\right)$ of DAM, CAUC, and CBR models in the two chemical-species combinations are 0.88 , 0.86 , and 0.88 , respectively (Table 5 ). The qualitative differences among the fits of the three models are small (Table 5), which means that all of the three models are capable of describing the $\operatorname{LC}_{50}(t)$ data in an accurate way.

Fig. 2D indicates the optimal fits of the three toxicity models to the $C_{\mathrm{L}, 50}(t)$ data in the $\mathrm{Zn}$-abalone system. The CAUC model fits the observed data with a high coefficient of determination $\left(r^{2}=0.94\right)$; however, neither the DAM nor the CBR model optimally fitted to the data. The DAM consistently overestimates the toxicity at short exposure times of about 24-96 h and substantially underestimates toxicity at exposure times longer than $120 \mathrm{~h}$, and the CBR model fails to reflect the time-dependent toxicity and to underestimate the lethal body concentrations obviously (Fig. 2D).

\subsection{Prediction of $C_{L, 50}(t)$ and assessment of EEC lethality}

The predicted $C_{\mathrm{L}, 50}(t)$ values from the three toxicity models in the As-tilapia system based on the input parameters estimated from $\mathrm{LC}_{50}(t)$ data are presented in Fig. 2B. The predicted $C_{\mathrm{L}, 50}$ values of CBR model are constant due to the model assumption, whereas the CAUC model shows a dramatic decrease initially from 210.99 to $26.93 \mu \mathrm{g} \mathrm{g}^{-1}$ in the 25th hour, then increasing slightly to $56.76 \mu \mathrm{g} \mathrm{g}^{-1}$ at the end of the simulation. The DAM shows an

Table 5

Coefficient of determination $\left(r^{2}\right)$ of the optimal fits of CBR, CAUC, and DAM models to $\operatorname{LC}_{50}(t)$ data and root mean square error (RMSE) of the predicted results of PD- and DAM-based survival models to survival data of different exposure levels in the duration of $96 \mathrm{~h}$ for As-tilapia and $\mathrm{Zn}$-abalone systems

\begin{tabular}{|c|c|c|c|c|c|}
\hline \multirow[t]{2}{*}{ Bioassay system } & \multicolumn{3}{|c|}{ Coefficient of determination $\left(r^{2}\right)$} & \multicolumn{2}{|c|}{ Root mean square error (RMSE) } \\
\hline & DAM & CAUC & $\mathrm{CBR}$ & DAM-based & PD-based \\
\hline As-tilapia system & 0.82 & 0.79 & 0.82 & 0.16 & 0.14 \\
\hline $\mathrm{Zn}$-abalone system & 0.94 & 0.92 & 0.94 & $0.30^{\mathrm{a}}$ & 0.24 \\
\hline & $0.88^{\mathrm{b}}$ & $0.86^{\mathrm{b}}$ & $0.88^{\mathrm{b}}$ & $0.17^{\mathrm{c}}$ & \\
\hline
\end{tabular}

\footnotetext{
${ }^{a}$ Predicted results with parameters estimated from $\mathrm{LC}_{50}(t)$ data.

b Average values of coefficient of determination.

${ }^{\mathrm{c}}$ Predicted results with parameters estimated from $C_{\mathrm{L}, 50}(t)$ data.
} 
unnoticeable decrease initially from 60.79 to 30.53 $\mu \mathrm{g} \mathrm{g}^{-1}$ in the fifth hour, then remains constant to the end of the simulation. It is impractical to accumulate such high concentrations in tilapia within an extremely short interval, initially. Consequently, the most accurate prediction seems to be given by
DAM and CBR models, yet the latter fails to describe the apparent time-dependent concentration of the $C_{\mathrm{L}, 50}(t)$ values.

The observed endpoint can be adjusted depending on the purpose of assessment, where we focus on the $50 \%$ mortality. Fig. $3 \mathrm{~A}$ indicates that when the tila-
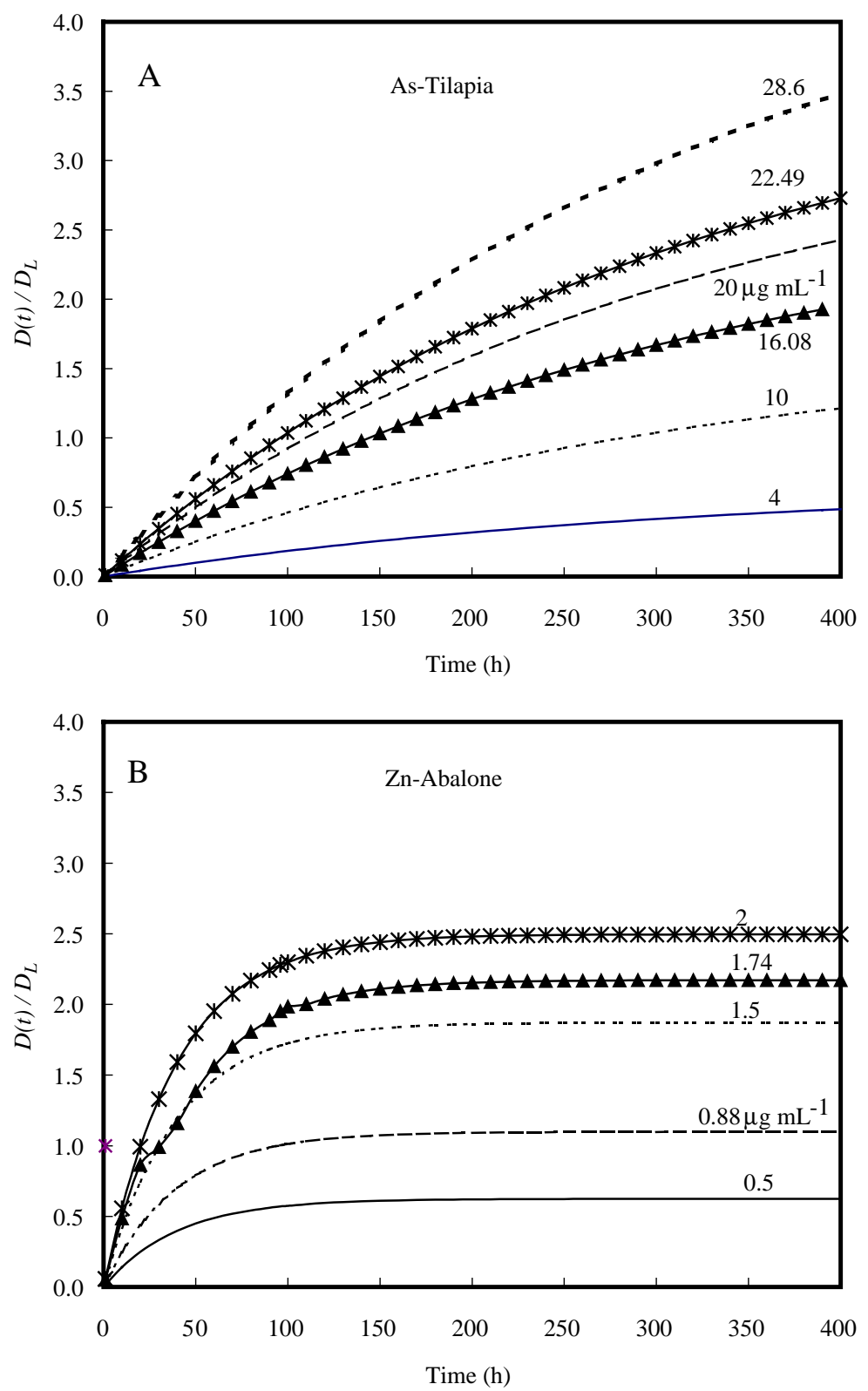

Fig. 3. The predicted $D(t) / D_{\mathrm{L}, 50}\left(=C_{\mathrm{w}} / \mathrm{LC}_{50}(t)\right)$ values of (A) As-tilapia and (B) $\mathrm{Zn}$-abalone systems in that when the curves exceed the value of $D(t) / D_{\mathrm{L}, 50}=1.0$, the $50 \%$ mortality will occur in the period $t$. 
pia are exposed to As concentration $\leq 4 \mu \mathrm{g} \mathrm{mL}-1$, the $50 \%$ mortality will never occur; the predicted $50 \%$ mortality occurring in $96 \mathrm{~h}$ and $144 \mathrm{~h}$ are 22.49 and $16.08 \mu \mathrm{g} \mathrm{mL}^{-1}$, respectively, both of which fall within the $95 \% \mathrm{CI}$ of the observed $\mathrm{LC}_{50}$ data (Table 4). Once the waterborne As levels rises to 10, 20, and $28.6 \mu \mathrm{g} \mathrm{mL}^{-1}$, the $50 \%$ mortality will occur in $280 \mathrm{~h}, 114 \mathrm{~h}$, and $78 \mathrm{~h}$, respectively. The lethality assessment of the $\mathrm{Zn}$-abalone system can be depicted from Fig. 3B in that the $50 \%$ mortality will never occur when abalone exposed to waterborne $\mathrm{Zn}$ is $\leq 0.5 \mu \mathrm{g} \mathrm{mL}-1$, with the predicted $50 \%$ mortality occurring in $24 \mathrm{~h}$ and $96 \mathrm{~h}$ being 1.74 and $0.88 \mu \mathrm{g} \mathrm{mL}^{-1}$, respectively, which also fall within the $95 \%$ CI of the observed LC $_{50}$ data (Table 4). Yet when the concentration rises to 1.5 and $2 \mu \mathrm{g}$ $\mathrm{mL}^{-1}$, mortality will occur in $30 \mathrm{~h}$ and $20 \mathrm{~h}$, respectively. Our study indicates that the DAM scheme provides a practicable tool to assess the time-concentration integrated lethality of EEC that organisms are supposed to be exposed.

\subsection{Validation of survival models and predictions of survival rate}

The optimal fits of the Hill equation (Eq. (8)) to the observed percent mortality of the 96-h acute toxicity test result in the estimated Hill coefficient of $n=4.07\left(r^{2}=0.93, p<0.05\right)$ and $3.70\left(r^{2}=0.98\right.$, $p<0.05)$, respectively, in the As-tilapia and $\mathrm{Zn}-$ abalone systems. We employed the DAM-based model (Eq. (1)) with input parameters estimated from two available data sets (Tables 2 and 3) and PD-based survival model (Eq. (7)) to simulate the concentration-dependent survival rates of two chemical-species combinations in the 96-h duration. Fig. 4 shows the comparison among observed data (mean \pm S.D.) and simulation results of DAM- and PD-based survival models. The corresponding root mean square error (RMSE) of simulations (Table 5) in the As-tilapia system (Fig. 4A) all fall within the standard deviation of observed data, which ranges from 0.13 to 0.21 ; however, only the survival curve of the DAM-based model with input parameters estimated from $C_{\mathrm{L}, 50}(t)$ data has the lowest root mean square error $(\mathrm{RMSE}=0.17)$ and also falls within the range of standard deviation (0-0.19) (Fig. 4B), whereas the other two models show slightly higher values (Table 5). Our analyses reveal that both of the two prediction tools are applicable to describe and predict the survival rates. Noticeably, the input parameters estimated from internal lethal concentration data will provide better performance on toxicity estimations than that from external effect concentrations.

The validation of the two survival models lets us apply them to predict the time-varying survival rate in extending chemical concentration ranges. Fig. 5 depicts a clear concentration-response relationship between waterborne chemical concentrations and survival. In DAM-based modeling, survival curves are exponentially decreasing as chemical concentrations increase (Fig. 5A and C) and rise with shorter durations in the two chemical-species combinations. The predicted survival curves by PD-based model display a similar trend with DAM-based model, yet the former one declined with sigmoid forms due to mechanistic characteristics (Fig. 5B and D). The DAM-based model shows a lazier slope than that in the PD-based model, revealing an easier concentration-response relationship, especially in short durations (i.e., in the durations of $24 \mathrm{~h}$ and $48 \mathrm{~h}$, the survival rate are 0.12 and 0.015 , respectively, when farmed tilapia were exposed to waterborne As of $250 \mu \mathrm{g} \mathrm{mL}^{-1}$ ). There was almost no tilapia survival when they were exposed to waterborne As of $150 \mu \mathrm{g} \mathrm{mL}^{-1}$ in corresponding durations of the PD-based model. Another finding is that the DAMbased model shows more noticeable decreases in the lower exposure levels. Our predictions obviously show the time-concentration integrated toxicity property, suggesting that these two survival models are applicable in predicting time-concentration integrated survival rates.

\section{Discussion}

\subsection{Characteristics of input and estimated parameters}

Because few previous studies have evaluated As toxicity to tilapia and $\mathrm{Zn}$ toxicity to abalone, we did not have an a priori estimate of internal lethal body concentrations. When only $\mathrm{LC}_{50}(t)$ data are available for the prediction of time-dependent toxicity, the 

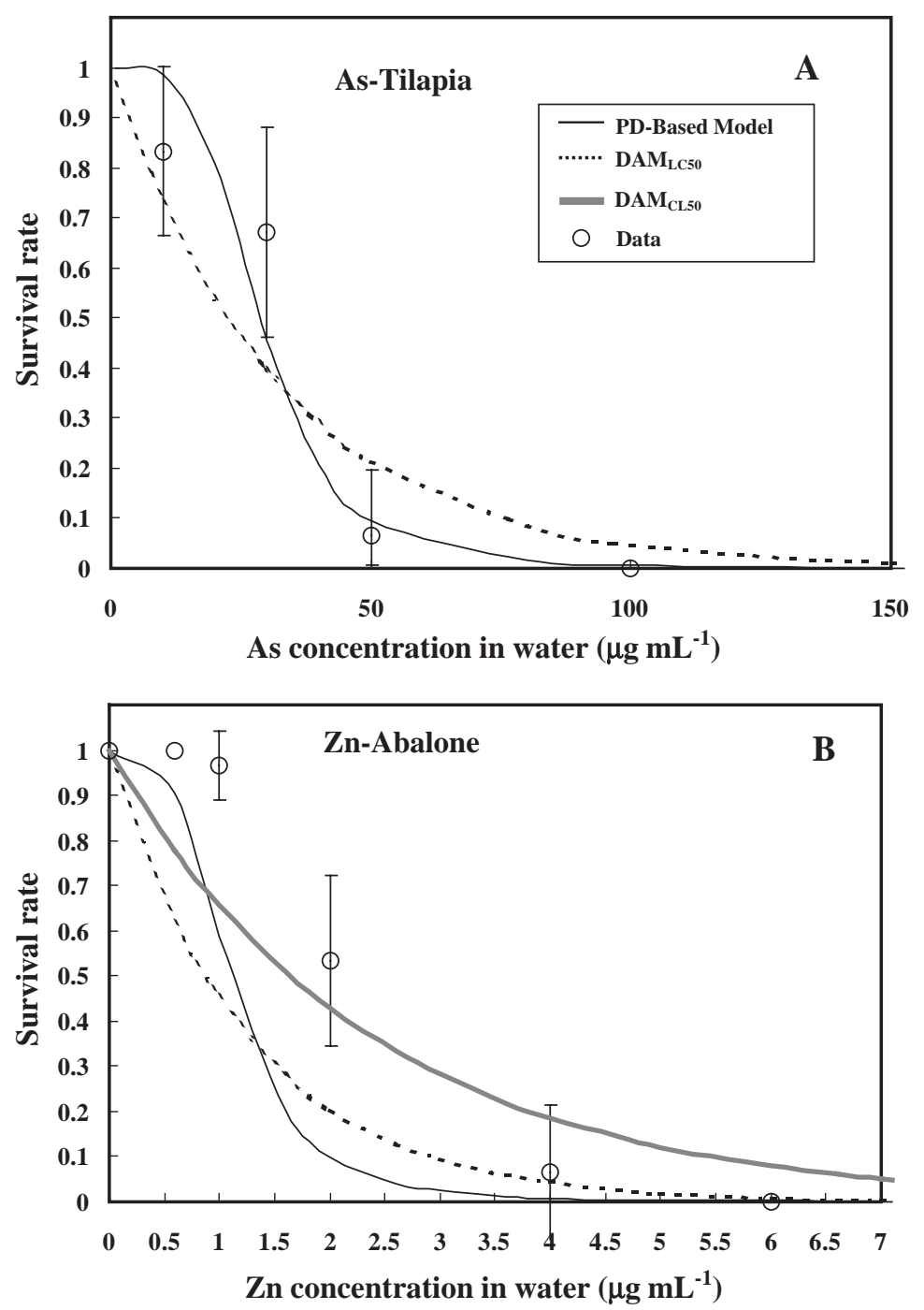

Fig. 4. Optimal fits of $96-\mathrm{h}_{50}$ data applied by DAM- and PD-based survival models for (A) As-tilapia and (B) Zn-abalone systems in that $\mathrm{DAM}_{\mathrm{LC} 50}$ and DAM $\mathrm{CL50}_{0}$ denote the parameters estimated from DAM-based model fitted to $\mathrm{LC}_{50}(t)$ and $C_{\mathrm{L}, 50}(t)$ data, respectively. Error bars show the $95 \%$ confidence interval of observed data from the mean.

CAUC model is capable of describing the chemicalspecific trends of $C_{\mathrm{L}, 50}$; however, the CBR model has limitations due to the mathematical formulation and model assumptions. Changing the assumptions could extend further studies.

The predicted $C_{\mathrm{L}, 50}$ values with input parameters estimated from $\mathrm{LC}_{50}(t)$ data by first-order one-compartment model may be unreliable due to variations from internal biological regular mechanisms of organism. Our study suggests that using the DAM-based survival model with biological parameters estimated from the $C_{\mathrm{L}, 50}(t)$ data can predict the time-concentration integrated survival rate accurately, comparable with traditional PD-based survival models. Therefore, to describe and predict toxicity dynamics, two different types of experiments need to be conducted using the same treatment levels at the same time, including bioassays for (i) gathering time-to-death data at a given exposure level, and (ii) biokinetic experiments to estimate kinetic parameters. 

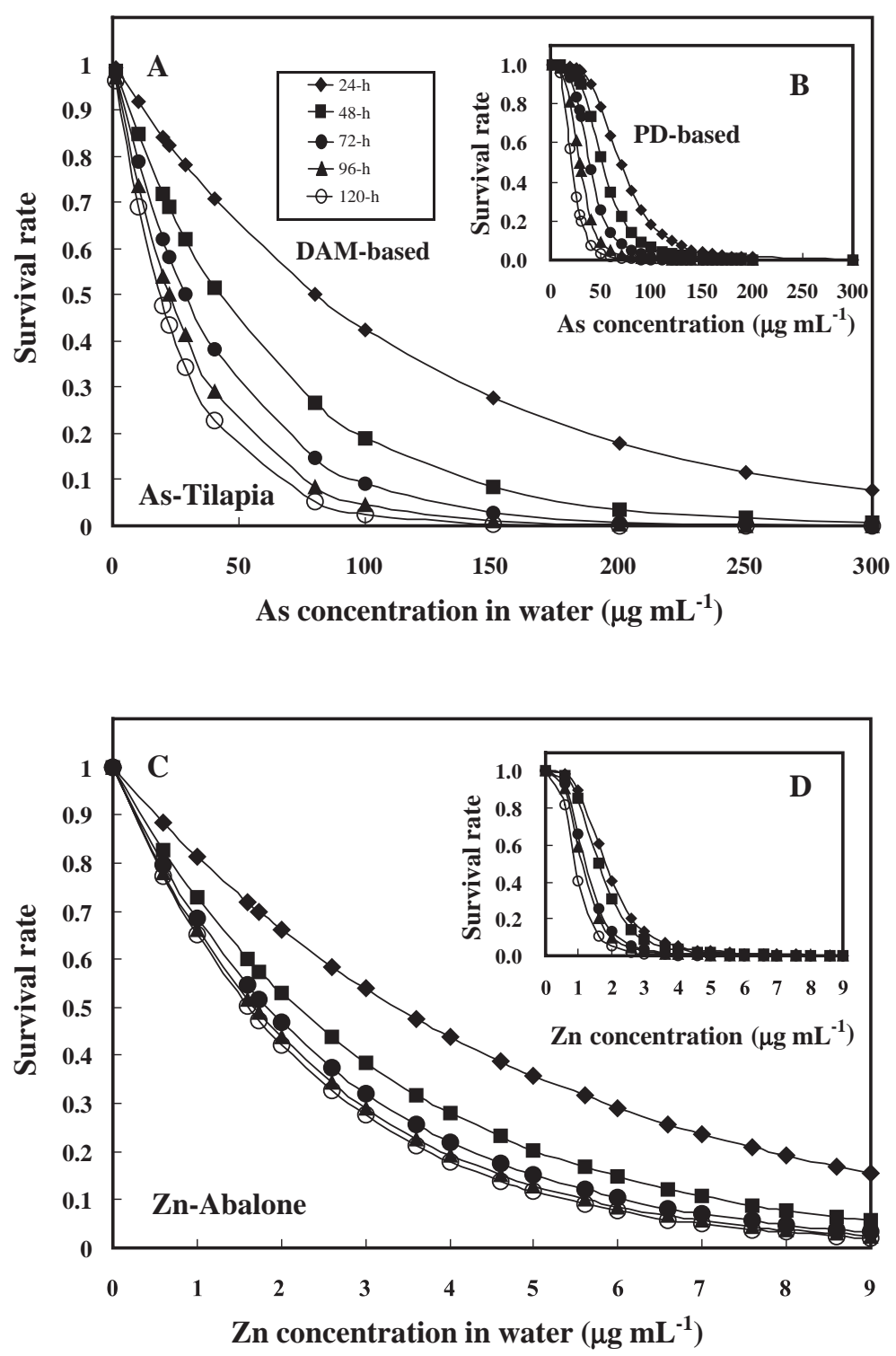

Fig. 5. Predicted survival rate profiles varied with different waterborne concentrations applied by DAM- and PD-based survival models, respectively, in (A and B) As-tilapia and (C and D) $\mathrm{Zn}$-abalone systems.

Parameters have to be analyzed in view of the biological assumptions of the models. The biokinetic parameters $k_{\mathrm{e}}$ should be interpreted on the basis of the first-order bioaccumulation model. The fit of a model might be strongly determined by the input parameters. Therefore, the uncertainties in the $k_{\mathrm{e}}$ value, which is an input parameter in the three toxicity models (Tables 2 and 3), affect the validation of the models. The experimental $\mathrm{LC}_{50}$ data of the As-tilapia and Zn-abalone systems support the validity of the three models, despite the uncertainties in the input parameter $k_{\mathrm{e}}$.

\subsection{Ecotoxicology of $\mathrm{Zn}$ and As}

Zinc is an essential element for all organisms. It plays critical role in a variety of biochemical processes including regulatory, structural, and enzymatic 
functions. Although $\mathrm{Zn}$ is essential, it is toxic at high concentrations (Koh et al., 1996). When the external concentration gets too high, the organism's homeostatic capacity will fail and toxicity effects will occur (Van Assche et al., 1997). The exact mechanism of Zn toxicity is not known. It has been suggested that $\mathrm{Zn}$ may bind to inappropriate intracellular ligands, or compete with other metal ions for enzyme actives sites, transporter proteins, etc., leading to toxicity (Gaither and Eide, 2001). In addition, evidence shows that high intracellular free $\mathrm{Zn}$ promotes neuronal death by inhibiting cellular energy production (Dineley et al., 2003).

Consequences of cellular $\mathrm{Zn}$ overload may include increased cellular reactive oxygen species (ROS) production, loss of mitochondrial membrane potential, and reduced cellular ATP levels (Dineley et al., 2003). Moreover, Zn non-enzymatically depleted glutathione (GSH), which leads to activation of the cellular death signal and, eventually, neuronal death (Chen and Liao, 2003). Further, it has been shown that $\mathrm{Zn}$ can exert toxic effects on aquatic organisms by inhibiting the uptake of Ca (Spry and Wood, 1985; Hogstrand et al., 1995). In contrast, there are several potential mechanisms that detoxify excess $\mathrm{Zn}$. These include the binding of the metal to cytoplasmic macromolecules such as metallothioneins (Hamer, 1986). Additionally, Zn transporters may help in detoxification by facilitating intracellular sequestration within organelles, or efflux of zinc across the plasma membrane (Gaither and Eide, 2001).

Arsenic is an environmental chemical of toxicological concern. Arsenic is a naturally occurring element, but anthropogenic activities can lead to a substantial contamination of the environment. The metabolism of As plays an important role in its toxicity. The metabolism involves reduction to a trivalent state and oxidative methylation to a pentavalent state (Scott et al., 1993). The exact mechanism(s) of cellular and molecular events associated with As toxicity is poorly understood but several hypotheses have been proposed. Trivalent arsenicals react in vitro with thiol-containing molecules such as GSH and cysteine (Scott et al., 1993; Delnomdedieu et al., 1994). The binding of trivalent As to critical thiol groups may inhibit important biochemical events that could lead to toxicity. In the pentavalent state, inorganic As may replace phos- phate in several reactions (Dixon, 1997), resulting in toxicity.

The major portion of the toxic effects of arsenate, however, may be due to its reduction to arsenite. Inorganic As is classified as a known human carcinogen. However, the precise mechanisms by which As acts as a carcinogen in humans remain to be elucidated. Because As can elicit many diverse effects, more than one mechanism may be involved in its carcinogenic effect (Hughes, 2002). Several mechanisms have been proposed. These include genotoxicity, cell proliferation, altered DNA repair and DNA methylation, oxidative stress, co-carcinogenesis, and tumor promotion (Hughes, 2002). A better understanding of the mechanism(s) of action of As will make a more confident determination of the risks associated with exposure to this chemical (Hughes, 2002).

\subsection{Implications}

Our results show that measured and predicted $\mathrm{LC}_{50}$ values decrease as the exposure time is extended and measured, and $C_{\mathrm{L}, 50}(t)$ increases slightly with increased exposure time. Since $\mathrm{Zn}$ is an important essential nutrient in maintaining a wide variety of biological processes in organisms, the total $\mathrm{Zn}$ content of tissues in abalone may not solely reflect on the toxic effect (mortality) of the metal. Therefore, the amount of required $\mathrm{Zn}$ at the target sites that causes mortality (i.e., the measured $C_{\mathrm{L}, 50}(t)$ value within the abalone for $\mathrm{Zn}$ ) is expected to be higher than those of nonessential elements. This finding well explained that the idea of the $\mathrm{LC}_{50}$ value only gives the ambient concentration that causes toxicity, whereas the CAUC approach gives more accurate and comparable measures of the bioavailable concentration that actually reaches the target site(s) within the organism and causes toxic effect (mortality). The CBR model fails to describe the apparent time dependence of the $C_{\mathrm{L}, 50}$ of $\mathrm{Zn}$ in abalone. The DAM overestimates the $C_{\mathrm{L}, 50}(t)$ value at short exposure times and underestimates the $C_{\mathrm{L}, 50}(t)$ values as time extends. In contrast, the CAUC model seems to give a more accurate prediction of the $C_{\mathrm{L}, 50}(t)$ of $\mathrm{Zn}$ in abalone.

The DAM, CAUC, and CBR models used in this study were initially developed for organic xenobiotics; however, the results from this study suggested that those models are applicable for metal toxicity 
prediction, both essential element $\mathrm{Zn}$ and nonessential element As in this case. This is not surprising since the toxicity of both metals has been suggested to be related to receptor interactions (Spry and Wood, 1985; Scott et al., 1993; Delnomdedieu et al., 1994; Hogstrand et al., 1995; McCloskey et al., 1996; Gaither and Eide, 2001; Di Toro et al., 2001; Dineley et al., 2003).

The integration of mechanistic models of DAM, CAUC, and CBR, together with the effective application of new knowledge on environmental risk assessment, should enhance ongoing and further strategies for establishing rigorous ambient water quality criteria aimed at protecting and restoring degraded aquacultural ecosystems.

\section{References}

Bedaux, J.J.M., Kooijman, S.A.L.M., 1994. Statistical analysis of bioassays, based on hazard modeling. Environ. Ecol. Stat. 1, B303-B314.

Bonnoment, V., Duboundin, C., Magaud, H., Thybaud, E., Vindimian, E., Beauzamy, B., 2002. Modeling explicitly and mechanistically median lethal concentration as a function of time for risk assessment. Environ. Toxicol. Chem. 2, 2252-2259.

Bourne, D.W.A., 1995. Mathematical Modeling of Pharmacokinetic Data. Technomic Publishing Company Inc., Lancaster, PA.

Chen, C.J., Liao, S.L., 2003. Zinc toxicity on neonatal cortical neurons: involvement of glutathione chelation. J. Neurochem. $85,443-453$.

Delnomdedieu, M., Basti, M.M., Otvos, J.D., Thomas, D.J., 1994. Reduction and binding of arsenate and dimethylarsinate by glutathione: a magnetic resonance study. Chem.-Biol. Interact. 90, 139-155.

De Vries, J., 1996. Toxicokinetics: quantitative aspects. In: Niesink, J.M., de Vries, J., Hollinger, M.A. (Eds.), Toxicology: Principles and Applications. CRC Press Inc., New York, pp. 136-183.

Dineley, K.E., Votyakova, T.V., Reynolds, I.J., 2003. Zinc inhibition of cellular energy production: implications for mitochondria and neurodegeneration. Neurochemistry $85,563-570$.

Di Toro, D.M., Allen, H.E., Bergman, H.L., Meyer, J.S., Paquin, P.R., Santore, R.C., 2001. Biotic ligand model of the acute toxicity of metals: 1 . Technical basis. Environ. Toxicol. Chem. 20, 2383-2396.

Dixon, H.B.F., 1997. The biochemical action of arsenic acids especially as phosphate analogues. Adv. Inorg. Chem. 44, 191-227.

Freidig, A.P., Verhaar, H.J.M., Hermens, J.L.M., 1999. Comparing the potency of chemicals with multiple modes of action in aquatic toxicology: acute toxicity due to narcosis versus reactive toxicity of acrylic compounds. Environ. Sci. Technol. 33, $3038-3043$.
French-McCay, D.P., 2002. Development and application of an oil toxicity and exposure model OilToxEx. Environ. Toxicol. Chem. 21, 2080-2094.

Gaither, L.A., Eide, D.J., 2001. Eukaryotic zinc transporters and their regulation. BioMetals 14, 251-270.

Hamer, D.H., 1986. Metallothionein. Annu. Rev. Biochem. 55, 913-951.

Hill, A.V., 1910. The possible effects of the aggregation of the molecules of haemoglobin on its dissociation curves. Proc. Physiol. Soc. 40, 4-7.

Hogstrand, C., Reid, S., Wood, C.M., 1995. $\mathrm{Ca}^{2+}$ versus $\mathrm{Zn}^{2+}$ transport in the gills of freshwater rainbow trout and the cost of adaptation to waterborne $\mathrm{Zn}^{2+}$. J. Exp. Biol. 198, 337-348.

Hughes, M.F., 2002. Arsenic toxicity and potential mechanisms of action. Toxicol. Lett. 133, 1-16.

Koh, J.Y., Suh, S.W., Gwag, B.J., He, Y.Y., Hsu, C.Y., Choi, D.W., 1996. The role of zinc in selective neuronal death after transient global cerebral ischemia. Science 272, 1013-1016.

Lee, J.H., Landrum, P.F., Koh, C.H., 2002a. Toxicokinetics and time-dependent PAH toxicity in amphiod Hyalella azteca. Environ. Sci. Technol. 36, 3124-3130.

Lee, J.H., Landrum, P.F., Koh, C.H., 2002b. Prediction of timedependent PAH toxicity in Hyalella azteca using a damage assessment model. Environ. Sci. Technol. 36, 3131-3138.

Legierse, K.C.H.M., Verhaar, H.J.M., de Bruijn, J.H.M., Herman, J.L.M., 1999. Analysis of the time-dependent acute aquatic toxicity of organophosphorus pesticides: the critical target occupation model. Environ. Sci. Technol. 33, 917-925.

Liao, C.M., Ling, M.P., 2004. Probabilistic risk assessment of abalone Haliotis diversicolor supertexta exposed to waterborne zinc. Environ. Pollut. 127, 217-227.

Liao, C.M., Chen, B.C., Lin, M.C., Chiu, H.M., Chou, Y.H., 2002. Coupling toxicokinetics and pharmacodynamics for predicting survival of abalone (Haliotis diversicolor supertexta) exposed to waterborne zinc. Environ. Toxicol. 17, 478-486.

Liao, C.M., Chen, B.C., Singh, S., Lin, M.C., Liu, C.W., Han, B.C., 2003. Acute toxicity and bioaccumulation of arsenic in tilapia (Oreochromis mossambicus) from a blackfoot disease area in Taiwan. Environ. Toxicol. 18, 252-259.

Liao, C.M., Chen, B.C., Tsai, J.W., Chen, J.W., Ling, M.P., Chou, Y.H., 2004. A parsimonious AUC-based biokinetic method to estimate relative bioavailable zinc to abalone Haliotis diversicolor supertexta. Aquaculture 232, 425-440.

McCarty, L.S., Mackay, D., 1993. Enhancing ecotoxicological modeling and assessment. Environ. Sci. Technol. 27, 1719-1728.

McCloskey, J.T., Newman, M., Clark, S., 1996. Predicting the relative toxicity of metal ions using ion characteristics: Microtox bioluminescence assay. Environ. Toxicol. Chem. 15, $1730-1737$.

Pery, A.R.R., Bedaux, J.J.M., Zonneveld, C., Kooijman, S.A.L.M., 2001. Analysis bioassays with time-varying concentrations. Water Res. 35, 3825-3832.

Scott, N., Hatlelid, K.M., MacKenzie, N.E., Carter, D.E., 1993. Reactions of arsenic(III) and $\operatorname{arsenic}(\mathrm{V})$ species with glutathione. Chem. Res. Toxicol. 6, 102-106.

Spry, D.J., Wood, C.M., 1985. Ion flux rates, acid-base status, and blood gases in rainbow trout, Salmo gairdneri, exposed to 
toxic zinc in natural soft water. Can. J. Fish Aquat. Sci. 42, $332-1341$

Van Assche, F., van Tiborg, W., Waeterschoot, H., 1997. Environmental risk assessment for essential elements, case study: zinc. In: Langley, E., Mangas, S. (Eds.), Zinc-Report of an International Meeting, National Environmental Health Forum Monographs, Metal Serious, vol. 2. South Australian Health Commission, Adelaide, pp. 33-47.
Verhaar, H.J.M., de Wolf, W., Dyer, S., Legierse, K.C.H.M., Seinen, W., Herman, J.L.M., 1999. An $\mathrm{LC}_{50}$ vs. time model for the aquatic toxicity of reactive and receptor-mediated compounds. Consequences for bioconcentration kinetics and risk assessment. Environ. Sci. Technol. 33, 758-763.

Widianarko, B., van Straalen, N., 1996. Toxicokinetics-based survival analysis in bioassays using nonpersistent chemicals. Environ. Toxicol. Chem. 15, 402-406. 